\title{
8 \\ Health Systems as Industrial Policy: Building Collaborative Capabilities in the Tanzanian and Kenyan Health Sectors and Their Local Suppliers
}

Maureen Mackintosh, Paula Tibandebage, Joan Kariuki Kungu, Mercy Karimi Njeru and Caroline Israel

\section{Introduction: health sector organization as implicit} industrial policy

A recognition that the demand patterns and investment incentives generated by health care and health policies constitute an 'implicit' industrial policy for manufacturers of medicines and medical supplies is not new. In a European context, Thomas (1994) argued that post-1945 UK health care pricing and regulation policies drove a shift to global competitiveness in the locally based pharmaceutical industry, while French post-war health policy did not. Reich (1990) has argued that Japanese success in pharmaceuticals was nurtured, not by the MITI's industrial policy, but mainly by government regulation and funding of the health sector and manipulation of pharmaceutical pricing.

The most sophisticated analyses of the health-industry relationships are by Indian and Brazilian scholars. Srinivas (2012) has analysed in depth the changing institutional relationships in India among the 'triad' of industrial production, health care provision/delivery and consumption of health care (Chapter 10) through three historically distinct 'market environments'. Brazilian scholars and policy makers have been addressing for three decades the development of a 
'health-industrial complex' (Chapter 9) consisting of a health sector aiming at universalization of access and framed by the constitutional right to health, the development of pharmaceutical, biotech and other medical supplies industries, and the supporting governmental institutions (D'Ávila Viana and Elias, 2007, citing pioneering analysis by Cordeiro, 1985; see also Gadelha et al., 2012; Shadlen and Massard da Fonseca, 2013).

This chapter examines health-industry interactions in two East African countries. The chapter traces the ways in which the health sector's institutional organization in each country influences the domestic markets for industrial supplies. We argue that the recent institutional evolution in the health sector has tended to undermine local manufacturers' linkages with their domestic health sectors in both countries, with a progressive disconnection in particular between public and non-profit health care procurement of medicines and supplies and local manufacturers seeking market access. Coupled with rising external competition in the private medicines markets in each country (Chapters 2 and 3), these institutional changes have driven a process of partial disconnection of domestic industrial-health market linkages in the two countries. The effect is most striking in Tanzania, where the industrial structure is less robust (Chapter 3).

We argue that to achieve better developmental synergies between industrial development in manufacturing medicines and health system performance, both health and industrial sectors have to strengthen what we call 'collaborative capabilities': the capability to respond effectively to the opportunities offered by the other sector. We identify key elements of these collaborative capabilities in each sector and trace some ways in which institutional evolution and changing market structures can move health and industrial supplier sectors towards or away from mutually beneficial trading and working relations with each other.

We then go on to explore the mediation of these interactions via the under-researched institutions of procurement and local marketing. Procurement and marketing, we argue, are culturally and politically rooted institutions, not mere policy instruments. We aim to demonstrate that policy coherence, which is essential to incentivizing healthindustry collaboration, is not only a matter of political will: it is itself a social construct that has to be built through institutional generation of collaborative capabilities and compatible incentive structures between health and industry at national level.

These conceptual arguments are developed through engagement with the findings from research undertaken in 2012-13 in Kenya and 
Tanzania, which investigated supply chains from local producers and importers into the health sector. ${ }^{1}$ Qualitative interviews and quantitative data collection on availability, source and price of a checklist of 'tracer' medicines ${ }^{2}$ and other essential supplies were conducted in both countries. In Tanzania, 42 health facilities (public, faith-based and private), pharmacies and drug shops across four very diverse districts were visited (Tibandebage et al., 2014), while in Kenya, 55 health facilities, pharmacies and shops were interviewed in a comparative study (Kariuki et al., 2015). Following these supply chain studies, wholesalers, manufacturers and policy and regulatory stakeholders were interviewed in both countries in 2013-14. This chapter draws also on some of these interviews, alongside secondary data sources.

\section{Health sector market structure}

In political economy terms, health sectors are not best understood as 'delivery systems' - the linear and top-down framing favoured in much of the global health literature. ${ }^{3}$ Rather, they represent complex and culturally embedded social institutions and important sectors of the economy whose evolution can be analysed using the tools of industrial economics. In almost all low- and middle-income countries, health sector institutions include widespread markets in services as well as commodities.

A key determinant of a health sector's capacity to procure and use medicines and other medical supplies effectively, and to develop good local suppliers, is therefore its market structures. These determine how the population's demand for and need for medicines feeds through (or fails to feed through) into wholesale purchasing; who are the resultant wholesale buyers of essential supplies; what market power those buyers exercise; and how they select and distribute supplies.

\section{Market and supply chain segmentation}

The Tanzanian and Kenyan health sectors, like many others in Africa, rely heavily on private individual expenditure for financing; hence, fees and charges operate as barriers to access to adequate health care for much of the population (Chuma and Okungu, 2011; Maluka, 2013). WHO data for 2012 estimate that private out-of-pocket (OOP) spending funded $48 \%$ of Kenyan health care, with another $6 \%$ from private insurance. The figures for Tanzania were $32 \%$ OOP, with negligible private insurance. ${ }^{4}$ Charges are applied quite widely in the public as well as private sectors in both countries. 
Private health care facilities, including for-profit, and faith-based and non-governmental non-profit facilities play a quite substantial role in each country. Private for-profit providers in Kenya run 27\% of the hospitals and virtually all the nursing homes and clinics. Over half of Kenyan hospitals and over $75 \%$ of the health centres and dispensaries, however, are government-owned and run, with the rest (around 17\% of each category) in the faith-based sector. ${ }^{5}$ Tanzanian data are not strictly comparable, but the for-profit sector in Tanzania appears relatively smaller, owning $16 \%$ of dispensaries, $3 \%$ of health centres and $15 \%$ of hospitals (but only $4 \%$ of hospital beds). The faith-based sector is relatively larger in Tanzania, including $42 \%$ of hospitals, some funded and run as part of the government system (MoHSW, 2009).

These differentiated health care sectors buy medicines through quite segmented supply chains in each country. In the 2012-13 study outlined above, the public sector sourced supplies overwhelmingly from one large public wholesaler in each country. ${ }^{6}$ Public facilities in Kenya had sourced $91 \%$ of the set of 'tracer' essential medicines from the public sector wholesaler, KEMSA. In Tanzania the comparable figure for public sector sourcing from the Medical Supplies Department (MSD) was 97\%. In Kenya, private facilities sourced $99 \%$ of these essential medicines from private wholesalers, in Tanzania 94\% (the main exception in each case was anti-retrovirals (ARVs) for HIV/AIDS sourced through the public sector). Only the non-profit facilities in Kenya had diverse wholesale sources, buying 44\% from a faith-based, non-profit wholesaler (MEDS), about one-third from private wholesalers, and sourcing the rest from the public sector. In Tanzania there is no large non-profit wholesaler; the faith-based facilities' medicines came largely (83\%) from private wholesalers, and the rest from the public sector.

However, a substantial proportion of essential medicines used by the population in these two countries, as across Sub-Saharan Africa (Wafula et al., 2013), is not accessed as part of treatment at a facility: rather, the medicines are bought in retail drug shops and pharmacies. Availability of essential medicines is limited and variable in the public sector in both countries, and public sector patients are often sent to shops to buy medicines out of pocket. ${ }^{7}$ There are no reliable estimates of the percentage of essential medicines accessed through the private shops in either country, in part because of gaps in household budget survey data (MoHSW, 2012). National Health Accounts do not separate medicines purchase from other facility spending (MoMS and MPHS, nd). The private shops were found to be entirely reliant on private wholesalers to source medicines. 


\section{Market power and local purchasing}

The implication of these market structures is that, with exceptions noted below, the final users and consumers of essential medicines exercise little influence over the sourcing and pricing of their medicines. That market power lies with the wholesalers and with some large funding bodies. The different sectors in the two countries exercise that market power to different effect in terms of local procurement of medicines.

Our supply chain data (Table 8.1) show that the public sector wholesaler in each country had bought a higher proportion of the tracer essential medicines from local manufacturers than had the private wholesalers. The faith-based wholesaler in Kenya (MEDS) was the most likely of all to source these medicines locally. All Kenyan wholesale sectors, furthermore, were more likely than their Tanzanian counterparts to buy these essential medicines from their local manufacturers (Table 8.1). Finally, while Tanzania buyers sourced medicines from Kenya ('other African' for Tanzania in Table 8.1 is largely Kenyan), the Kenyan buyers bought little from non-Kenyan African suppliers.

To what extent are these different patterns of local purchasing summarized in Table 8.1 generated from the health sector side, from the manufacturing capabilities side, and from effective institutional cross-sector interaction? We begin by examining in turn the public, donor, nonprofit and private purchasing practices and their implications for health system capability and willingness to purchase effectively and economically from local suppliers.

Table 8.1 Country of origin of tracer essential medicines, by procurement sector, Tanzania and Kenya, 2012-13 (\% by sector)

\begin{tabular}{|c|c|c|c|c|c|}
\hline \multirow{3}{*}{$\begin{array}{l}\text { Country } \\
\text { Source }\end{array}$} & \multicolumn{2}{|c|}{ Tanzania } & \multicolumn{3}{|c|}{ Kenya } \\
\hline & \multicolumn{2}{|c|}{ Wholesale sector } & \multicolumn{3}{|c|}{ Wholesale sector } \\
\hline & Public & Private & Public & Faith-based & Private \\
\hline Domestic manufacturers & 22 & 11 & 53 & 76 & 33 \\
\hline Other African & 10 & 21 & 0 & 0 & 6 \\
\hline India and Pakistan & 49 & 50 & 30 & 11 & 31 \\
\hline China & 6 & 6 & 8 & 1 & 4 \\
\hline EU and Switzerland & 7 & 11 & 1 & 4 & 19 \\
\hline Other & 6 & 0 & 7 & 8 & 7 \\
\hline Total & 100 & 100 & 100 & 100 & 100 \\
\hline
\end{tabular}

Note: Numbers may not add to 100 because of rounding. 


\section{Public sector procurement capabilities}

\section{The view from 'below'}

Interviews with clinical and administrative staff in public sector facilities in both countries about their experiences of procurement belie the image in the aggregated data above, of clearly segmented supply chains. The view from 'below' was not of a single linear public sector ordering process, but was more like navigating an interactive maze while constantly distracted by clinical demands.

In all the lower-level health facilities (dispensaries, health centres, smaller clinics), most people doing procurement were nurses and clinical officers doing it as part of the day job ${ }^{8}$ :

Like me now, who is a clinician, I do almost everything, I am the procurement person, I am seeing the patients. (Clinical officer, Kenyan public health centre)

The only institutions that might have procurement officers with specialist training were larger hospitals: there, pharmacists, laboratory in-charges, nurses and medical directors would be involved, and teamwork was emphasized. A high-end private hospital in Nairobi felt they were coping:

I can tell you in a hospital like this you will really need team work. We have trained everybody on inventory management. What they need to keep in terms of safety stock versus ensuring they have re order levels. (Hospital pharmacist, Kenyan private hospital)

Procurement staff in a stressed Tanzania urban district hospital by contrast felt they lacked the capabilities needed to do this well:

This is a big hospital that has different departments.... Some are slow while some are sharp. This delays the process...departments that were quick in submitting their items... keep knocking at our doors asking for their order. We have to tell them, procurement process is under way, while waiting for other department to submit theirs. They get angry because patients are waiting at their doors. (Procurement officer, Tanzanian public hospital)

Procurement, like all aspects of health care, is social and relational. Though form-filling is required, the ordering and control systems work 
well only where institutional relationships stitch them into responding to health care needs on the one hand, and into effective and timely supply systems on the other hand.

In both countries, there were almost universal complaints about long delays and incompletely or inaccurately filled orders from the public wholesaler. Availability of our tracer medicines in public hospitals was $61 \%$ in Kenya and $86 \%$ in Tanzania; these were all items hospitals should have held. The corresponding figures for the lower-level public facilities were $48 \%$ in Kenya and 58\% in Tanzania. The prevalence of 'stock-outs' at the public wholesaler was thus a fact of life in both countries, forcing a search for alternative sources of supply. Patients were sent to shops to buy missing medicines, and in both countries many found it unaffordable. Among many examples, a health centre interviewee serving low-income patients in Kenya commented that in cases of antibiotic resistance, 'sometimes you are forced to write a prescription to that patient [for another type of antibiotic] but you see the patients we deal with are the less privileged people', so some just went untreated.

Keeping essential items on the shelves was a constant struggle. The alternatives public sector staff turned to when stocks failed included spending user fees to fill gaps, using other pockets of public and donorsupported funds, borrowing between public sector facilities, soliciting personal and institutional donations and even spending their own money.

How these pressures feel can be illustrated from interviews in two public dispensaries and a public hospital in a single rural district of Tanzania. In the two dispensaries, procurement was done by a clinical officer in-charge. They had no procurement training. They ordered most of their medicines from the public wholesaler every three months, via the district medical officer (DMO), and struggled with missing essential items and resultant accusations from patients of mismanagement or corruption. Opening the consignments was overseen by a local village health committee.

All collected fees from patients, but only the hospital retained them; the dispensaries deposited them with the DMO. The DMO had access to a donor-supported 'basket' fund; like the budgets for the district at the public wholesaler, these were sometimes deposited with a delay. The dispensaries applied to the DMO for gap-filling from the 'basket'; the hospital also used its fees for this purpose. The hospital pharmacist would cycle off directly to buy urgent essentials at district-designated pharmacies. In the hospital, most essential medicines on our list were there, but barely, with little backup stock. 
An exception was items provided by 'vertical programmes' via the DMO, such as test kits for HIV, malaria and pregnancy. These were generally available but had to be collected from the district centre - a challenge for rural dispensaries with no petty cash and no means of transport. Staff paid for their own transport if no lifts could be found: one remarked, 'this is not correct'. Medical equipment was the most problematic item: 'even if you order them, you do not get them, so we do not order them ... we ask donors to help'. One clinical officer displayed thermometers obtained from a Dutch personal donor, a blood pressure machine sent to him by a friend in the United States and a stethoscope he had bought himself: individual networks of local rural sourcing were thus quite globalized.

Kenyan local-level experience echoes this complexity. There, public sector lower-level facilities obtained their KEMSA supplies through the local district hospital. The parallels to the 'basket funds' were the Health Sector Services Fund (HSSF) and Facility Improvement Funds (FIF), and they also used fees and charges. In addition, there was in Kenya a widespread local culture of borrowing between public facilities, especially when patients could not afford to buy medicines in the shops, and especially in the rural districts: in these circumstances,

We usually borrow from other facilities, and they also borrow from us. (Nurse in-charge, Kenyan rural public dispensary)

\section{Donor influence and government leverage}

Local-level public sector procurement staff had little influence over decisions on wholesale procurement of medicines from different manufacturing sources. Some, when asked, had views and preferences on where medicines should be bought, commenting for example on problems of packaging of locally manufactured items, or positively on patients' acceptance of local brands. But decisions on manufacturing source of medicines in both countries were taken at wholesale level with little or no reference to facility-level views.

The public sector procurement bodies, KEMSA and MSD, sourced their medicines largely through international open tenders. ${ }^{9}$ MSD is an autonomous government department working on a commercial basis $^{10}$; KEMSA was, until 2013, a government agency, and is now an authority. Tendering by both authorities is strongly price-focussed, and most tenders are very large. The emphasis on open tendering has effectively liberalized the public sector medicines market in both countries. Both bodies can give $15 \%$ price preference to local manufacturers in 
competition with imported products. In Tanzania, local manufacturers argue, this equates to around $9 \%$ effective preference, since they deliver to MSD, while overseas suppliers deliver to the port of entry. ${ }^{11}$ In Kenya, some local manufacturers complain the preference is not reliably applied (UNIDO, 2010: 9).

In both countries, public procurement practices for medicines are strongly influenced by tendering rules promoted by the multilaterals and other donors; they are also shaped by requirements of the large donors providing medicines funding. The very large international tenders have helped to control tendering costs and improve confidence in the public procurement process. ${ }^{12}$ The biggest institutional evolution in both countries' medicines markets in the last decade has been the growth of large-scale donor-funded procurement of medicines for TB, HIV/AIDS and malaria. Around 63\% of MSD's income from medicines and medical supplies came from these 'vertical programmes' in 2011-12, and this percentage varies sharply year on year (MSD, 2013). In Kenya, the latest estimate we have found is for 2005-06, when the government budget share of total public expenditure on medicines was estimated at $21.6 \%$, the bulk of the expenditure being donor-financed (MMs and MPHS, 2010: 53).

For donor-funded medicines, there is substantial international participation and control of pooled procurement processes by organizations such John Snow International and Management Sciences for Health within the Partnership for Supply Chain Management. ${ }^{13}$ The donors' emphasis has been on generating a global supply management chain for very high volumes of imports into East Africa, from 'pre-qualified', generally Asian suppliers to regional level in Africa. The pre-qualification process, run by the World Health Organization (WHO) ${ }^{14}$ to approve specified products of individual suppliers, has in practice largely excluded local manufacturers in both countries from the domestic markets for these products (see also Chapters 2, 3 and 5).

International donors also fund other essential medicines, including other public medicines' procurement. The 'basket' fund in Tanzania, mentioned above, is donor-funded. The flows of support are complex, erratic, poorly documented, generally unconsolidated and uncoordinated, and sometimes provided in-kind, as shown by 'spaghetti' diagrams of hugely complex financing and in-kind flows for medicines supply in each country (KEMSA Task Force, 2008: 28; MoHSW, 2008: 23).

In these circumstances, how much leverage do national governments exert over their domestic medicines markets and procurement? Leverage over procurement patterns can be exerted through national regulatory 
policies - for example, by setting tendering rules and coordinating funding flows. However, the extent to which the national governments contribute funds to the medicines procurement 'pot' remains an important element of policy leverage. Data are poor, but estimates drawn from national health accounts and policy documents suggest that in each county, only around 5\% of the domestic medicines consumption is currently funded by the government taxes.

For Tanzania, the domestic market size for medicines was estimated at around US\$250 million in 2011-12. ${ }^{15}$ Of this market, public wholesaler (MSD) sales were around 50\% (US\$125 million), of which 70\% in turn were donor-funded vertical programme sales (MSD, 2013). That leaves just US\$37.2 million as government-funded MSD procurement, or 15\% of the total market. However, the Ministry of Health and Social Welfare has estimated that only around $30 \%$ of the pooled public funds held by public health facilities in accounts at MSD for medicines and medical supplies were locally tax funded, equating to around US\$11.3 million, the rest coming from donor basket funds (MoHSW, 2013: 4-5). The implication is that just $5 \%$ of Tanzanian medicines were tax-funded in 2011-12.

A parallel calculation for Kenya could only be drawn from the most recent Kenyan National Health Accounts (MMS and MPHS, nd). They show total health spending (THE) for 2009-10 as US\$1.62 billion. The Kenyan National Pharmaceutical Policy (NPP) (MoMS and MPHS, 2010: 53-54) estimates total pharmaceutical expenditure (TPE) at around $20 \%$ of THE, or US $\$ 324$ million; of that 'about $15-20 \%$ ' was public expenditure, or around US\$64.8 million. Finally, the same document states (p. 53) that government spending was estimated in 2005-06 at $21.6 \%$ of public spending on medicines, the rest being donor funded. If that percentage were stable over time, it would imply a government tax-funded share of the Kenyan domestic medicines market in 2009-10 of under $5 \%$.

None of these calculations is at all secure. But they are sufficiently similar and striking to indicate a strategic policy constraint for both governments. The market size estimates are likely to be low rather than high: UNIDO's Kenyan review (2010: 36) concluded of their own calculations that 'not all, if any, of the donor-funded supply of medicines is included in such [market size] estimates'. Policy documents in both countries indicate very high reliance on donor funding of medicines (MoMS, 2010). The robust conclusion for both countries is that the governments exercise very little tax-funded leverage over their domestic medicines markets in relation to both need and demand. Both 
governments' leverage at present depends almost solely on regulatory interventions. These data also suggest that, over time, it will be important to shift tax resources into the medicines funding stream.

\section{Non-profit wholesaling: a case study of local procurement}

Non-profit wholesalers and distributors can have a beneficial impact on essential medicines markets, providing low-priced competition in the supply of quality-assured medicines (Mackintosh et al., 2011). Both Tanzania and Kenya have non-profit medicines wholesalers supplying the faith-based and NGO sectors. Those in Tanzania, Action Medeor and MEMS, are small, while MEDS in Kenya is a large wholesaler with a turnover of about US\$15 million in $2012^{16}$ and therefore with substantial market impact. Action Medeor was supplying both faith-based and government facilities, and also selling to the Accredited Drug Dispensing Outlets (ADDOs), the regulated drug shops in Tanzania. It was, however, too small a supplier to appear in our Tanzania facility survey data. MEDS, on the other hand, supplied most of the faith-based and NGO facilities interviewed in Kenya.

The interviews showed that MEDS had a good reputation among those procuring medicines for faith-based and non-profit facilities. The two main reasons given for reliance on MEDS were price first and also reliance on their quality assurance. There was general agreement that they were cheap: not always the cheapest, but a combination of cheapness and reliability of quality and supply.

MEDS was also regarded as responsive to its clients on quality, responding to queries and complaints, taking back problematic supplies, and consulting on its stock lists. MEDS is working in a market context, where facilities have a choice of supplier, and it also responded to requests concerning the brands and origins of specific medicines, and to consider suggestions for new items. They would also order items not held in their stocks, and they maintained short delivery times (1-3 days) for stocked items. They were serving a differentiated faithbased health sector, with facilities serving higher-income groups and those serving the very disadvantaged, and they might stock more than one brand of the same item if preferences of customers require. They warned in advance when phasing out items from their stock lists, or when a shortage arose. They gave some credit: 'we pay at the end of the month and they do not push us' (Kenya, faith-based clinic). 'They are very reliable', one interviewee remarked. This was a remarkably positive set of assessments. 
Both Action Medeor and MEDS had a strong orientation towards buying locally, subject to quality and price considerations. Action Medeor stated on its website: 'Most of our products are purchased locally in line with Action Medeor's policy to support local manufacturers however, without compromising on quality'. ${ }^{17}$ Given the limitations of Tanzanian suppliers (Chapter 3), Action Medeor was in practice buying from manufacturers in the East African region, notably Kenya and Uganda, as well as Tanzania. ${ }^{18}$ Both Action Medeor and MEDS organized their procurement by 'pre-qualifying' local suppliers, using their own technical staff for inspections, site visits and questionnaires. MEDS kept suppliers 'on their toes' through batch testing of supplies on-site in their WHO-prequalified laboratory.

As Table 8.1 showed, MEDS was buying a high proportion of their basic essential medicines from local manufacturers. This success in local purchasing reflected a strong capability for local procurement built up over a number of years. ${ }^{19}$ In contrast to the Kenyan public wholesaler, MEDS issues only local tenders for medicines and supplies, with no direct importing. Two local tenders a year go only to MEDS's pre-qualified supplier pool of local manufacturers and distributors.

Price is a very important component of MEDS's tender acceptance, but as private businesses, non-profit wholesalers such as MEDS can make their own supplier decisions, and price may not be the only consideration. ${ }^{20}$ Both quality and supplier performance, including lead times and meeting delivery deadlines, influence MEDS's supply decisions. Local manufacturers can provide short lead times and reliable quality if working relationships are good. Furthermore, MEDS sustains its working relationships with suppliers through an annual invitation-only suppliers' conference during which issues are discussed and tender documents are generally available so that suppliers can plan ahead.

In our 2012-13 data, two local manufacturers had supplied nearly $70 \%$ of the tracer items sourced from MEDS: local firms producing a broad range of basic formulations can generally compete on the required mix of price and performance, though they can be beaten on price by imports. While MEDS leans towards regularly inspected local suppliers for basic essential medicines, donors' subsidized procurement arrangements, for example of the first-line anti-malarial medication, has meant a lack of local supply, and local distributors import those items for MEDS.

This case study of MEDS suggests some lessons about effective local procurement and supply, working with local suppliers and faith-based facilities. That capability is now being tested, as the decentralization reforms allow counties to switch suppliers, causing demand for MEDS' 
services to rise sharply from new buyers who lack experience in quantifying demand, and may delay payment. ${ }^{21}$ The market segmentation identified from our data is now breaking down, as MEDS and KEMSA are effectively in competition (PSP4H, 2014; Yadav, 2014).

\section{Private sector procurement and local products}

The public, donor and non-profit procurement of medicines is important for medicines access. However, in both countries, half of medicines access or more relies on private sector wholesaling and importing. The interviews with private facilities and shops demonstrate that, in both countries, private retailers and clinicians rely almost wholly on private wholesalers. While most smaller buyers had little influence over the sources of the medicines they bought, many had opinions on the best sources of medicines, as did their patients. Asked systematically about the comparison between locally produced and imported medicines, the respondents' views varied according to their clientele. Some high-end private hospitals in Kenya, when procuring medicines, specified brands preferred by their patients, notably from European suppliers. Some pharmacies in better-off areas also said there was resistance to locally made branded generics.

Generally, however, the facilities and shops with lower-income clientele, who were buying from private wholesalers, would focus on price. Where the local items were price competitive, their clients would generally accept local brands, especially some, such as Shelys in Tanzania, which had built up a strong brand image (Mujinja et al., 2014). While in Tanzania opinions varied as to whether locally made medicines were cheaper or more expensive than imports, the consensus in Kenya was that local items tended to be cheaper:

By the way the locally manufactured drugs are cheap and the people who go for them are the health facilities in upcountry.... mission hospitals, clinics, district hospitals and local pharmacists in upcountry, they really support local manufacturers. (Private hospital, Kenya)

Most private retailers and facilities in both countries had built up longterm relationships with one or a few private wholesalers/importers, from whom they bought most of their supplies. The determinants of choice of supplier were predominantly price and credit terms, followed by issues such as transport arrangements and variety of items available. None could judge quality except through expiry dates and experience 
of clinical effectiveness, and only one interviewee had changed supplier for quality reasons: they found near-expiry drugs repackaged, more than once, as longer-dated on the external packaging, and changed supplier as a response.

The interrelated issues of price and credit terms were key: private shops and facilities are often struggling to maintain cash flow themselves, so they are looking for credit from suppliers. This was quite a typical comment:

The main reasons why I chose those wholesale pharmacies are the prices of the drugs, quality and the convenience each of them offers. [Pharmacy $\mathrm{X}]$ is my number one priority because for most medicines they have the lowest prices. (Tanzanian rural private dispensary)

This was the type of credit relationship that sustained many small drug shops:

[Pharmacy Y] can give medicines on a loan basis without any collateral provided what you take from the pharmacy does not exceed $400,000 /=$ [Tanzanian] Shillings, and you pay after selling, in one or two months' time. (Rural drug shop, ${ }^{22}$ Tanzania)

The main criticisms of locally manufactured medicines raised by private sector respondents in both countries concerned packaging, which was said to compare poorly with imported competing items, putting off users. In Tanzania, there was repeated criticism that some locally manufactured tablets tended to disintegrate too easily, and some unfavourable comparisons with the quality of Kenyan manufactured tablets.

The decisions of private wholesalers were therefore important to the local manufacturers' domestic market demand. Kenyan manufactured medicines were quite widely imported into Tanzania by the private wholesalers (Table 8.1; see also Chapter 2), while there were few Tanzanian items found in the Kenyan market. The Tanzanian private market was more heavily reliant on India (Table 8.1).

In both countries, many private wholesalers are also importers, who act as representative agents for Indian and European manufacturers. If margins are better on imported items, then importers will lack incentives to source and distribute local manufactures. Some large wholesalers/ importers supply only imported products, while others also deal in local products. Some importers, such as Phillips, have worked closely with a number of donor-funded projects, for example distributing imported 
subsidized anti-malarials and importing items for PEFAR-funded gapfilling supplies for donors' projects.

There are also wholesalers who have retail chains, and supply other retailers, and in both countries they buy locally as well as from importers. One such pharmaceutical wholesaler in Tanzania explained that there was demand for both Tanzanian and Kenyan medicines; however, there were constant shortages of Tanzanian items, whereas 'Kenyan products are always available in the market'. Kenyan suppliers such as Elys have representatives in Tanzania, and their products are widely distributed there.

\section{Local manufacturers' collaborative capabilities}

An important difference between the two countries is in the scale of the local pharmaceutical industry and the range of products the firms have the capability to supply (Chapters 2 and 3). While Tanzania had just five operating firms when the 2013 research was done, Kenya had about 40 producers, including firms capable of supplying parenterals manufactured in sterile conditions. The density in itself meant that Kenyan firms were more able than Tanzanian firms to supply their local market. However, they still currently (2013) supply only around $25 \%$ of the domestic demand (Chapter 2). There is clearly room for expansion of local supply in both countries.

In both countries, local manufacturers are strongly oriented to supplying the private market. Despite sharp price competition from imports and a lack of trade protection in the private market, Kenyan producers are continuing to compete successfully. One contribution to this price competitiveness appears to be export success: Kenyan manufacturers have expanded exports to the region (Chapter 2), allowing them to build up economies of scale and keep prices down. In addition to sales through local wholesalers, at least one large manufacturer in Tanzania had developed its own marketing teams to ensure wide product availability and brand recognition across the very large geographical distances in that country.

However, in both countries, there were problems concerning supply to the public wholesaler, and also problems of policy directions that were undermining the competitiveness of the local industry. The problem was sharper in Tanzania (Chapter 3). Even in Kenya, however, at least one large manufacturer had moved away from public sector tendering, citing KEMSA's focus on the lowest possible price, in order to build up higher-margin exports. Some larger Kenyan firms, with an expanding 
product range, continued to tender successfully. In Tanzania, some local manufacturers had shifted to supplying the public sector through local private wholesalers, who could carry the costs of bundling local and imported items and also carry some of the tendering costs and associated risks.

Furthermore, in both countries, there had been tax and tariff decisions that had undermined local manufacturers' competitiveness. In Kenya, manufacturers and distributors noted that the 2013 decision to impose VAT on inputs for pharmaceutical production was forcing up prices and undermining market access. In Tanzania, as Chapter 3 documents, the removal of tariffs on final goods, associated with VAT and tariffs on some inputs, was a substantial problem for the sustainability of the whole industry. In Kenya, however, the manufacturers' associations had made strong representations, and in 2014 this was amended to exempt inputs or raw materials for pharmaceutical manufacturing in Kenya. ${ }^{23}$ However, the amendment was silent on packaging: the Kenyan manufacturers had previously fought successfully to remove taxes from packaging inputs, and had then seen those gains reversed. It appears that Kenyan manufacturers' associations are able to exert more influence over relevant policies than their equivalents in Tanzania.

However, local manufacturers in the two countries have historically struggled to exert influence over policies of donors. Many donor policies have excluded local firms from domestic market segments, the most damaging having been the loss of most of the regional anti-malarials markets to donor-subsidized, WHO-prequalified external suppliers. The extent of local firms' collaboration with external donors and multilaterals has, however, been increasing recently. Examples include working with WHO and UNIDO projects to support technological upgrading; working with charities such as Drugs for Neglected Diseases (DNDi) to implement new formulations and achieve pre-qualification; and working with PEPFAR to supply gap-filling medicines to donor projects. This process of learning to exert influence and benefit from collaborative projects is an important element of firms' learning and upgrading in the strongly donor-influenced regulatory and policy environments within which these firms work.

\section{Conclusion: building collaborative capabilities}

The sharp process of institutional change in the health systems and medicines financing in Kenya and Tanzania has faced the largely locally owned manufacturers of medicines currently working in the two countries with 
major shifts in market structure, regulation, demand patterns and the political economy of policy influence. The big changes have included increasing liberalization and 'globalization' of the domestic markets for medicines, associated with a growing private health and retail pharmacy sector, especially strong in Kenya, and a sharp rise in the variety and volume of imports on the market.

The public sector market has also been globalized, with increasing donor pressure for large-scale open international tenders, pooled procurement and a ruthless focus on price. Donors have been able to exert leverage for this evolution because of the huge increase in external funding provided for medicines and the need for reform because of earlier problems with public tendering processes. One outcome has been a dominant international 'framing' of the supply chains and procurement issues as a challenge in linking 'pre-qualified' external suppliers to local patients. Barriers to domestic market entry for local firms were raised by these institutional changes, and domestic market linkages disaggregated.

Now, these disaggregated linkages need to be substantially and collaboratively rebuilt, and then sustained in a very open market environment. For this purpose, there is a highly important role for government. Key policy objectives should be to institute and enforce measures to enhance medicines access through public and faith-based facilities in the health sectors within both countries, and to shift procurement incentives towards encouraging purchasing from local suppliers.

At the same time, these policies can only be effective if they are designed in collaboration with the market actors who must build and manage the market linkages that allow effective domestic market supply. The MEDS example, though operating in a specific niche, suggests some of the key elements for the rebuilding of market linkages between health and industrial sectors. They include active consultation and working relationships between procurement agents and supplier firms; pre-qualification of local suppliers, with a strong element of quality control; and a necessary level of business autonomy in procurement decisions on price/quality trade-offs.

Some of these elements are observable also within public sector procurement and can be built upon to create cumulative improvement. Some medical and other supplies (such as furniture items) are bought by the public wholesalers from local suppliers under more flexible purchasing arrangements. Local firms actively produce and supply emergency items (and resent being called upon in this way after they have lost earlier tenders). Furthermore, the public wholesalers have the 
financial capability to offer more active collaboration, in the form of longer contract to incentivize suppliers' investments, and better credit terms, if they wish to do so. In Kenya, the decentralization reforms have given KEMSA more autonomy while shifting some demand to MEDS (PSP4H, 2014).

This (re)building of domestic linkages has to be done in the context, not only of high levels of external competition but also in the face of the very high level in each country of 'fragmentation' (Chuma and Okungu, 2011; McIntyre et al., 2008) in health financing, procurement, service supply and management, and in a context where government expenditure exerts little domestic market leverage, as documented above. Policy coherence between health and industrial policies, an essential objective for governments seeking developmental synergies, is not merely a set of government decisions, but a social construction that has to be built over time through institutional generation of collaborative capabilities in both sectors, and associated incentives for extracting mutual benefit. The Ethiopian governments' effort to combine health-sector improvement with industrial-sector support (Chapter 4) identifies the relevance of health-sector restructuring for strengthening local health-industry collaboration. The Brazilian experience explored in the next chapter reinforces this point.

\section{Notes}

1. This chapter is based on the research project Industrial productivity and health sector performance. The findings, interpretations, conclusions and opinions expressed are those of the authors and do not necessarily reflect the views or policies of DFID or the UK ESRC, whose financial support is gratefully acknowledged (project ES/J008737/1). Particular thanks to all our interviewees, who gave time within very pressured lives to talk to us, often at considerable length. Thanks also to participants in a Policy Dialogue workshop in REPOA, Dar es Salaam, June 2013, at which early findings from these surveys were presented and discussed, and to Watu Wamae for research collaboration and for comments on an earlier draft. The same disclaimer applies.

2. In Kenya, a set of 29 essential medicines, including ARVs, were used for the quantitative data collection (Kariuki et al., 2015); in Tanzania, a comparable set of 24 medicines was used (Tibandebage et al., 2014); the differences were largely the result of differing treatment regimes between the two countries.

3. For example, the WHO Health Systems Framework and its 'building blocks' are a framework for service delivery; http://www.wpro.who.int/health_services/health_systems_framework/en/. See also Kim et al. (2013) for the rise of 'health care delivery science' in the global health field.

4. WHO Global Health Observatory, http://apps.who.int/gho/data/node. main.78?lang=en (accessed 3 March 2015) (Kenya); http://apps.who.int/gho/ data/node.main.75?lang=en (accessed 20 November 2014) (Tanzania). 
5. Calculated by the authors from Ministry of Health, Health Management Information Systems data for 2010.

6. These data were collected in Kenya before the decentralization reforms that have allowed counties to diversify procurement sources for public health sector supplies.

7. Source: quantitative data and interviews, 2012-13.

8. All quotations are from fieldwork unless otherwise stated.

9. Source: interviews, KEMSA website, http://www.kemsa.co.ke/, UNIDO (2010).

10. http://www.msd.or.tz/index.php/aboutus/msd-organizationconsulted (accessed 27 March 2015).

11. Source: interviews.

12. Source interviews, see also Yadav (2014) and MSD (2013).

13. http://pfscm.org/pfscm consulted 6/3/15.

14. See http://apps.who.int/prequal/ consulted 27/3/15.

15. Source, interviews.

16. Calculated from MEDS (2013: 38), from sales of KShs 1.413 billion.

17. http://medeor.de/en/medeor-tanzania/purchasing-information.html (accessed 1 April 2015).

18. Source: interviews.

19. Source: interviews.

20. An HAI/WHO assessment of medicines procurement prices in 2004 confirmed this perception independently: MEDS procurement prices were somewhat higher than KEMSA procurement prices, though both were paying low prices by international standards; http://www.who.int/medicines/areas/technical_ cooperation/MedicinepricesKenya.pdf (accessed 29 March 2015).

21. MEDS (2013) confirms a problem of rising debt that has to be addressed.

22. This shop was an Accredited Drug Dispensing Outlet (ADDO).

23. By the Value Added Tax (Amendment) Act, No. 7 of 2014, Kenya. Inputs or raw materials (either procured locally or imported) supplied to pharmaceutical manufacturers in Kenya for manufacturing of medicaments, as approved from time to time by the Cabinet Secretary for National Treasury in consultation with the Cabinet Secretary responsible for health, were added to list of exempts.

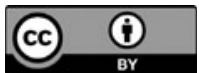

Except where otherwise noted, this work is licensed under a Creative Commons Attribution 4.0 Unported License. To view a copy of this license, visit https://creativecommons.org/version4 